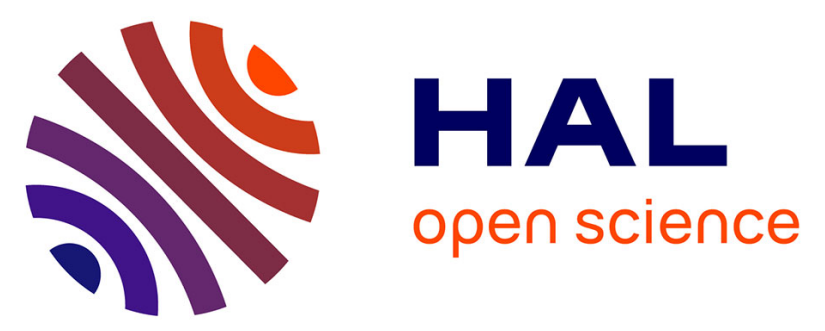

\title{
A Multi-level Perspective on Digital Platform Implementation and Impact: The Case of EasyTaxi in Colombia
}

\author{
Juan Erasmo Gomez-Morantes, Richard Heeks, Richard Duncombe
}

\section{To cite this version:}

Juan Erasmo Gomez-Morantes, Richard Heeks, Richard Duncombe. A Multi-level Perspective on Digital Platform Implementation and Impact: The Case of EasyTaxi in Colombia. 15th International Conference on Social Implications of Computers in Developing Countries (ICT4D), May 2019, Dar es Salaam, Tanzania. pp.195-206, 10.1007/978-3-030-18400-1_16 . hal-02285264

\author{
HAL Id: hal-02285264 \\ https://hal.inria.fr/hal-02285264
}

Submitted on 12 Sep 2019

HAL is a multi-disciplinary open access archive for the deposit and dissemination of scientific research documents, whether they are published or not. The documents may come from teaching and research institutions in France or abroad, or from public or private research centers.
L'archive ouverte pluridisciplinaire HAL, est destinée au dépôt et à la diffusion de documents scientifiques de niveau recherche, publiés ou non, émanant des établissements d'enseignement et de recherche français ou étrangers, des laboratoires publics ou privés. 


\title{
A Multi-Level Perspective on Digital Platform Implementation and Impact: The Case of EasyTaxi in Colombia
}

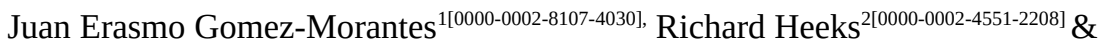 \\ Richard Duncombe ${ }^{2[0000-0001-5690-3012]}$ \\ ${ }^{1}$ Systems Engineering Dept, Pontificia Universidad Javeriana, Colombia \\ je.gomezm@javeriana.edu.co \\ ${ }^{2}$ Centre for Development Informatics, University of Manchester, UK \\ richard.heeks@manchester.ac.uk¹,richard.duncombe@manchester.ac.uk
}

\begin{abstract}
Growth of digital platforms in developing countries has yet to see equivalent growth in research. This paper presents one of the first conceptualised analyses of platform implementation and impact. Using the "multi-level perspective", it analyses a successful ride-hailing platform: EasyTaxi in Bogotá, Colombia. This was originally a niche innovation but has effected a socio-technical transition to a dominant position within Bogotás taxi regime. Speed of transition is explained in terms of tensions within that regime and from wider demographic change, combined with specific utility of the platform to drivers and passengers who faced a prior context of exploitation, mistrust and insecurity. Though the new regime is a hybrid of platform and nonplatform features, its impacts can already be seen: datafication, formalisation, and shift in power away from old taxi operating companies and towards passengers and, in particular, towards the platform itself. Alongside casespecific insights, the paper demonstrates the utility of the multi-level perspective as a means to analyse the enactment of digital platforms.
\end{abstract}

Keywords: digital platform, socio-technical transitions, multi-level perspective, ride-hailing

\section{Introduction}

Digital platforms - "a set of digital resources - including services and content - that enable value-creating interactions between external producers and consumers" [5:p381] - play a rapidly-growing role in the socio-economic life of developing countries [18]. Yet the research literature is dominated by studies focused on the global North, leaving knowledge gaps along the entire lifecycle of platforms in the South: design-implementation-adoption-impact [ibid.].

This paper contributes with one of the first case studies of a developing country digital platform analysing implementation and impact; selecting EasyTaxi - a ridehailing platform first developed in Brazil, though the focus here is its role in the capital, Bogotá, of neighbouring Colombia. First introduced in Colombia in late 2012, within less than three years EasyTaxi dominated the taxi bookings market, prompting

\footnotetext{
Corresponding author
} 
our first research question to explain why such a rapid change took place. We secondly wish to understand the nature of this change: not just the micro-level of taxi bookings but the broader structural impacts of digital platform introduction. To help shape our analysis, we understand platform-based change as a socio-technical transition; specifically using the 'multi-level perspective' (MLP) as a frame [10]. Following a review of literature and methods, the paper presents MLP-structured findings, and then conclusions.

\section{Literature Review}

The rapid global spread of digital platforms is partly real because of the billions of users adopting them and partly terminological as 'platform' has become a label of choice attached to the likes of Google, Facebook, iTunes, Uber, etc. This rapid growth has been matched by a growth of published research on platforms, yet there has been a serious research lag such that, for example, research agenda-setting papers are only just emerging [6]. This is especially true of work on platforms in developing countries: as one indicator, in the three leading ICT4D journals ${ }^{2}$ there are only six published papers with 'platform' in the title; all published since late 2016.

This was part of a more systematic review of 76 papers on digital platforms in developing countries ${ }^{3}$. More than half were computer science papers that focused on platform design and architecture, and the next largest group were design-oriented, analysing context or intended adoption (e.g. using the Technology Acceptance Model) in order to inform platform design. There was a group of six papers looking at broader strategy, such as best practice for platform governance or design of the wider platform ecosystem. Another group of six looked at current use of particular platform functions, mainly of e-learning and social media platforms.

Only three papers looked at the implementation of platforms, and their focus was mainly on challenges to adoption. Only one [21] drew out factors behind successful adoption. Using an actor-network theory sensitisation, it identified the need for platforms to incentivise use among multiple user groups if they are to succeed. Five papers analysed impact ${ }^{4}$ in some way; of these four were positivist in approach, providing a quantitative analysis of micro-level impact e.g. on individual behaviour. One [29] looked specifically at ride-hailing platforms in India and focused on driver livelihoods, with drivers reporting income and skill increases.

The review thus found no papers to date addressing the two questions - on speed of adoption, and the broad picture of impact - that inform this study. Where a concep-

2 Information Technology for Development, Information Technologies \& International Development, Electronic Journal of Information Systems in Developing Countries [15].

3 This searched three sources for "platform" in the title: the three ICT4D journals; the same search in the three leading development studies journals (World Development, Journal of Development Studies, Development and Change) which identified no relevant papers; and a Google Scholar search - intitle:"platform" (digital AND “developing countries” AND “information systems”). In total, this identified 76 relevant papers.

4 As might be expected there was some sense of research chronology, with earlier papers focusing on design and feasibility issues, and with implementation- and impact-oriented studies only emerging later. 
tual framework was used to shape analysis - and often there was no such framework or concepts were induced from the analysis - then this was a patchwork of different ideas. Given this, alongside lack of theory directly addressing our questions, it was appropriate that we looked outside the platform studies literature for our conceptualisation.

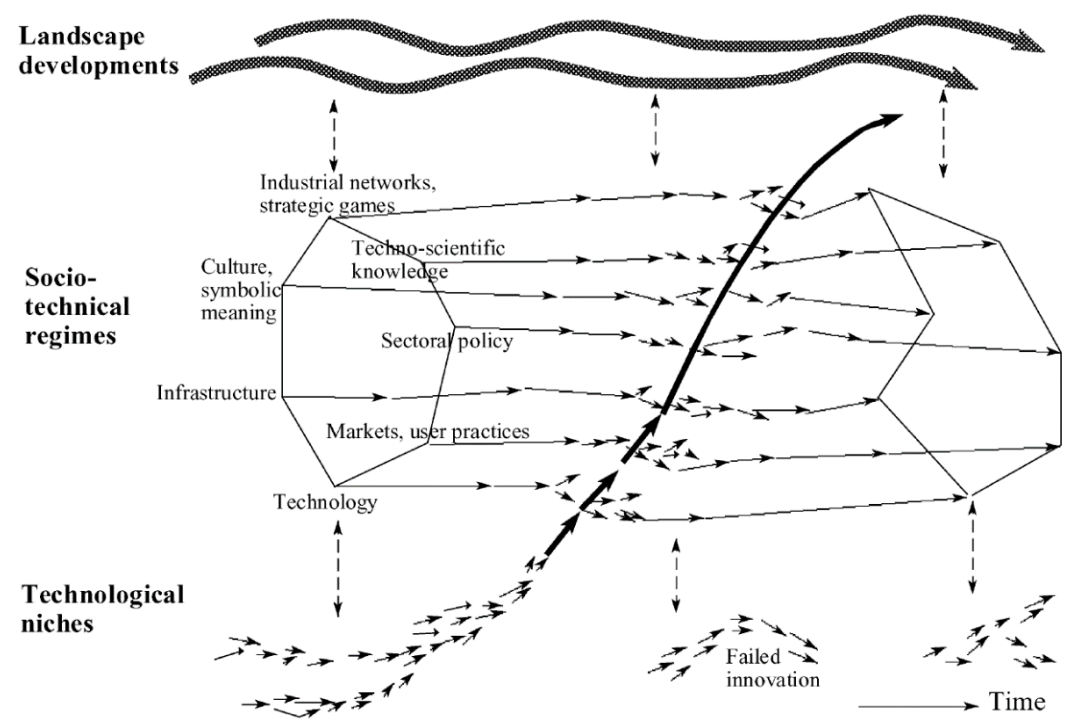

Fig. 1. The Multi-Level Perspective on Socio-Technical Transitions [8].

Because of our focus on change but also the need - described in the literature above - to incorporate issues such as human incentives, groups and livelihoods alongside the technology of the platform, we identified equivalence between the introduction of digital platforms and the idea of socio-technical transitions: changes from one socio-technical configuration to another [8]. In particular we saw the relevance of the conception of socio-technical transition via the multi-level perspective [ibid., 9]. Summarising significantly (see also Figure 1), this focuses on three elements, understood to operate at different levels:

- The broader landscape of long-term “demographical trends, political ideologies, societal values, and macro-economic patterns" [11:p28] that are "beyond the direct influence of actors” [9:p913]. This represents the wider context within which a socio-technical regime operates.

- The socio-technical regime: a configuration of linked elements including "technology, user practices and application domains (markets), symbolic meaning of technology, infrastructure, industry structure, policy and technoscientific knowledge” [8:p1262] that guide the activities of actors in some common endeavour. The definition of regime elements differs between writings on MLP and, in our analysis, we will organise these into four regime elements, drawing on Geels [12] and Scott [27]. These are: resources (physical artefacts such as technology but also intangible assets such as data), routines (standard 
processes and practices), relations (social connections between actors), and institutions (both formal such as regulations and informal such as discourse). These are not only seen to structure activity but also - germane to our later analysis - to constitute the key components of power within the multi-level perspective [1]. The boundary for the "common endeavour" will in our case be the taxi sector in Bogotá, within which a socio-technical transition - introduction and widespread adoption of a digital platform - occurs.

- The technological niche is a relatively protected space within which learning and innovation can occur. As indicated in Figure 1, innovations typically make their way into contact with the existing regime. Some fail but others succeed and, in doing so, they reconfigure the regime; transitioning it from one socio-technical system to another.

Although this has not yet, to our knowledge, been applied for analysis of digital platforms, the MLP framing offers a relatively comprehensive way to understand the wider development implications of introduction of platforms: both factors that shape the transition to a platform-based regime, and the changes that occur in that transition.

\section{Methods}

We adopted a case study research strategy: not only, as our literature review indicated, has this been typical of analyses of digital platforms [see also 6] but it was also specifically relevant to the type of questions around impact and speed of platform adoption that we wished to answer [4,31]. We selected EasyTaxi for three main reasons: the rapidity and extent of its adoption made it a platform success story: one that has sustained and has had sufficient impact to warrant analysis; it is representative of a type of platform now operating in most developing country cities, making it of general interest; and key stakeholders were willing to participate in data gathering. It can also be seen as fairly typical of digital platforms: both referring to itself as a platform and fitting the definition given above because it provides digital resources (an app, location-based mapping, rating scheme, etc) that enable value-creating interactions (taxi bookings and journeys) between external service producers (taxi drivers) and consumers (passengers) with EasyTaxi acting as platform intermediary for this two-sided market. Though the phone-/tablet-based app is the most visible component, it is the back-end, server-based platform that holds the power of data, data analysis, and market/driver management.

Interview schedules were designed around the multi-level perspective framework (landscape, regime components, niche innovation), and 24 interviews were conducted in total: 14 with taxi drivers (both users and non-users of EasyTaxi), 4 with EasyTaxi managers, 3 with central and city government officials, and 3 with other stakeholders (taxi owners, union officials). In addition there was a form of participant observation in being a passenger-user of EasyTaxi, and secondary documentation analysed included commercial brochures, regulatory documents, and news articles. Transcribed notes from all sources were combined and analysed using NVivo; with a first coding cycle using attribute and descriptive coding techniques then being refined and categorised based on the MLP [25]. 
Findings

\subsection{The Pre-Existing Regime}

Travel by taxi makes up 8\% of motorised journeys in Bogotá [24] and, in terms of routine practices, Bogotás yellow cabs pick passengers either through on-street hailing or through pre-booking. Historically, pre-booking was made by phone to one of the city's taxi operating companies (TOCs) that owned memorable phone numbers (e.g. 211-1111) and also owned radio frequency licences. The booking would generally be communicated to drivers via an open radio call from the TOC despatcher with the first driver to arrive at the location getting the fare: "They cut each other off, one of them would jump into the pavement, and they could even get into a fist fight in the street. It was terrible" (Taxi Driver 1). During the early 2010s, a few taxis had a GPSbased screen system installed with on-screen response. Taxi owners - it was relatively rare that drivers would own their vehicle [24] - paid a monthly rodamiento fee to the TOCs: affiliation to a TOC was an operational requirement. The fee ranged from around US\$18 without a radio (i.e. just on-street hailing) up to c.US\$55 for affiliation with GPS installation. Drivers also had to register with a TOC, though this was often quite informal. Drivers paid the owner a flat-rate fee per shift of around US $\$ 45$ plus a deposit (c.US\$175) and daily ‘savings' (c.US\$2.50) that are accrued against any accident damage to the cab; they also paid fuel costs (c.US\$20) and a daily carwash fee (c.US\$2.50).

The oligopoly power of taxi operating companies - three-quarters of taxis were affiliated to just five TOCs [16] - was based on resources and relations: the power of easy-recall phone numbers, the cost and scarcity of radio frequency licences, and contacts with national and local transport regulators. Taxi owner power but also competitive pressures arose from scarcity of taxi operating licences as a resource: capped at 50,000 since the early 1990s, the cost of buying a taxi operating licence from an existing owner had risen to more than US $\$ 40,000$ by the mid-2010s. Looking at drivers, the industry was described as a "receptacle of poverty" (City Official): high unemployment and poor social security pushed individuals to take up taxi driving in order to earn money, and there was strong competition for work. From a resource dependency perspective, then, TOCs and owners could readily substitute drivers, and this served to weaken the power of driver unions. Other social institutions - such as those of law enforcement - also had weaknesses which shaped the regime.

This provided some basis of stability for the regime in terms of main actors: regulatory institutions were unchanging; barriers to entry were so high for TOCs and even for taxi owners that their structures were static; and the churn of individual taxi drivers made little difference to the regime.

However, these factors also underpinned tensions that created a backed-up pressure for change. Three resource-competitive forces intersected on drivers; from taxi owners for earnings, from other drivers competing for fares, and from the pool of unemployed who could substitute them. These led to various over-competitive practices among drivers: refusing passengers wanting low-value journeys; aggressive driving to reach a potential fare first and to complete journeys quickly; refusing to use the meter 
and other forms of overcharging; hacking the meter in order to extract higher earnings; complicity in robbery of passengers [see also 3, 7, 22). TOCs had some power to address this through sacking or fining drivers: however, drivers could register from scratch - with a clean record - with a different TOC (though taking a hit on earnings when moving to one with a smaller market share). Poverty, criminality and institutional weakness within wider Colombian society led to "millionaire rides" (fake drivers and accomplices robbing passengers by taking them to one ATM after another to obtain cash) and felonious passengers robbing taxi drivers (who generally only transacted in cash). Whatever the actual prevalence of these activities, it was their widespread profile that fostered insecurity and mistrust of drivers and passengers.

Mistrust was also rife between drivers and owners/TOCs because of the perceived exploitative nature of their relationship with asymmetries of risk-bearing and valuetaking. TOCs were seen as rent-seekers, monetising their resource oligopoly but not intervening in disputes between owners and drivers, not training drivers, and assuming no responsibility for the quality of the service, the working conditions of drivers, or the cars: "the TOCs won't help you with anything" (Taxi Driver 2). Efforts to regularise the employment status of drivers e.g. to provide training, insurance, pensions were blocked by the TOCs. Owners bore some risk but, if they had problems with drivers e.g. around sickness or late payments, they just got rid of them. Drivers bore the main costs and risks: accidents, breakdowns, robbery, traffic tickets, lack of passengers, and being stuck in Bogotá's congestion were all their problem. When fuel prices rose, that ate into their earnings. Owners sometimes faced increased costs e.g. if the rodamiento charge was increased, and sometimes faced increased earnings opportunities e.g. if city-wide fares were increased. In either case, they increased the tariff charge to drivers; passing on cost rises, capturing price rises.

\subsection{The Landscape}

If fracture lines were apparent within the regime, they were opened further by landscape pressures. As noted, the number of taxi licences had been static for $>20$ years; yet, during that same period, the population of Bogotá rose from $5.5 \mathrm{~m}$ to $8 \mathrm{~m}$. Combined with GNI per capita growth from US $\$ 1,000$ to c.US $\$ 7,000$, urban mobility and demand for transportation increased significantly, making it increasingly difficult for passengers - often middle-class and politically-vocal - to get a taxi during peak hours. At the same time, the technological terrain was shifting. Colombia is only an average digital economy performer in regional terms but the Ministry of ICT has helped create reasonable competition, pricing, portability of numbers, and service quality in the mobile broadband market [20]. Supported by a growing ecosystem of mobile/broadband service providers and phone/tablet suppliers, retailers and repairers; mobile penetration rose from 6 subscriptions per 100 people in 2000 to 120 per 100 in 2015; mobile broadband rose from 9 per 100 in 2009 to 42 per 100 in 2015 [17].

\subsection{The Niche Innovation}

Into this highly-susceptible context of internal and external pressures stepped EasyTaxi as a personal transportation digital platform. At its core is a smartphone app 
bringing a different routine. Passengers register their details on the platform via the app and place a journey start/end booking; the first available driver to respond gets the booking; the passenger can then see the driver location, estimated time to pick-up, driver/vehicle details, and estimated fare; the app tracks the journey, and at the end the passenger can rate the driver and other aspects of the trip. Passengers can register and pay in-app via credit card, but in practice the great majority of payments are still made by cash (drivers are less likely to accept pay-by-card bookings). While guided by the EasyTaxi estimate, fares are still calculated by taxi-meter and according to the standard tariff set by the city transport department. Once drivers are registered, they are charged a US $\$ 0.30$ per-booking fee which decreases the greater the number of bookings in a given month (a very different philosophy from the flat-fee payment drivers must make to the cab's owners). The app is just the interface for the underlying platform which captures all the data; estimated at up to 300,000 passenger/driver requests per minute across all of EasyTaxi's multi-country operations [2].

EasyTaxi's design had to provide utility to two main groups: drivers and passengers. For drivers, the promise is that they will get more bookings more easily with fairer treatment and, more powerfully and particularly as network effects take hold, there is the threat of losing business if not registered with EasyTaxi. For passengers, there is a greater sense of certainty and security that the app confirms the booking, allows them to track the taxi, and to know and check the identity of their driver.

Network effects are a major challenge for digital platforms seeking to effect a socio-technical transition: the value of the platform to users increases exponentially as more buyers and sellers join and, hence, the platform must rapidly recruit both. Thus platforms may not readily have the type of protection seen as typical for niche innovations: time free from market and other pressures of the existing regime in order to learn, build relationships, revise designs, etc [8]. However, EasyTaxi was able to protect itself in three ways in Brazil (EasyTaxi Manager 1, see also 19, 23, 26, 28). During 2011, the development team attended three start-up "boot camp"-type events (winning competitions in each) that enabled highly-accelerated learning, iteration and relationship building with key business, urban governance and finance stakeholders. During 2012-2013, EasyTaxi received successive rounds of substantial external finance that provided time and space for further revisions but also to build the base of users to a sufficient level. And the agile, "lean start-up" approach used by the development team greatly reduced the protection time required for innovation. For the Colombia implementation, the original Brazil developments represent a protected niche from which a near-complete product could be transferred ${ }^{5}$.

Like all platform implementations, roll-out in Colombia faced a series of barriers but, in part due to learning from the earlier implementation in Brazil, these were relatively easily surmounted. Regulatory barriers and the social capital of existing taxi firms were sidestepped when the government accepted ET's argument that it was a communications services, falling just under the jurisdiction of the Ministry of ICT, rather than a transportation service, which would have fallen under the multiple jurisdictions of the National Transit and Transportation Ministry, the Ports and Transport

5 Though a number of local customisations were still required e.g. around ways to specify passenger location; something notoriously difficult in Bogotá and other Colombian cities. 
Superintendency, and agencies within Bogotá City Council. Taxi drivers lacked phones - fewer than 1\% had smartphones in 2012 (EasyTaxi Manager 1) - and capabilities to use them, so EasyTaxi sent its marketers to lunch or rest spots "where drivers concentrate" (EasyTaxi Manager 2). They lent out smartphones, ran training courses and offered free test periods during which no charge was made until they had built a critical mass of drivers and passengers. That critical mass was essential in overcoming the epistemic barrier of awareness: an advertising and promotional campaign was run but word of mouth - from drivers to other drivers, from drivers to passengers, from passengers to drivers - was key to diffusion and adoption. By the end of 2015, there were more than 55,000 driver-users in Colombia (up from 18,000 two years previously and from zero four years previously ${ }^{6}$ ); it was being used by the majority of drivers in Bogotá (though often in combination with other apps). EasyTaxi had a claimed $90 \%$ market share of ride-hailing apps in Colombia ${ }^{7}$ and the great majority of driver bookings now came from EasyTaxi not the traditional radio/GPS system. Competition has also, at least to some extent, been addressed. TOCs tried to stop drivers using the platform, but in vain: "What they've done is try to talk to taxi drivers, tell them "look, if you use EasyTaxi, you cannot work with us". At the end, when EasyTaxi starts to send more bookings than [TOCs], that threat, to put it that way, loses its value" (EasyTaxi Manager 1). Attempts by TOCs to set up their own app largely failed with only Taxis Libres surviving, and then only with small market share. Local firm Tappsi launched at around the same time. While it existed as a separate app until 2018, the firm was bought and then steadily merged into EasyTaxi's operations from late 2015. Only Uber, which launched “quietly” in 2013 has presented serious competition since around 2015. But it has faced far more aggression from traditional taxi firms, owners and drivers and from government than has EasyTaxi because it does not work with the traditional, licensed yellow taxi drivers [14, 30]. This has worked to the advantage of EasyTaxi as Uber, rather than it, has acted as the lightning rod for resistance to change in the taxi industry.

\subsection{Regime Transition}

As per the model above, we look here at four regime elements that change during the transition: routines, relations, resources and institutions. EasyTaxi inscribes into the app elements of the journey process and captures data about them for its platform; elements that were not previously formally recorded: booking, passenger and driver locations, directions to reach the passenger, reporting the passenger on board, cancellations, journey route and completion, passenger rating of driver. Data that was largely lost in the past is thus now owned by the platform, which has allowed it to undertake data-based algorithmic management. At an operational level, for example, it checks that drivers adhere to certain performance standards and intervenes if they fall short. At a more strategic level, it analyses booking demand patterns and advises drivers about prime times and locations. Notwithstanding ownership of data by the platform, some is shared: passengers get critical data they previously lacked: the visual identity

\footnotetext{
By 2018, this was 110,000 with more than two million passenger-journeys per month [13].

7 Though this includes EasyTaxi’s merger with Tappsi.
} 
and rating of their driver, type of taxi, the taxi's exact location and route; and drivers also get new data e.g. a record of their bookings and estimated fares.

The technology ownership system has changed. Memorable phone numbers are still owned by the TOCs, but their value was steadily diminishing as more bookings were made via the digital platform. Radio and GPS systems were typically owned by the TOC and rented by owners but drivers own their smartphones/tablets themselves. The multi-functionality of these devices has also been exploited by drivers: they use Waze / Google Maps to find their way to passengers and to plot journeys; they use WhatsApp to share information with other drivers about accidents, road blocks, or police operations. But one notable feature was that - while the old GPS systems had been ditched since EasyTaxi had rendered them redundant - radios were still retained in most cabs. A central feature of a taxi platform is that it disintermediates the despatcher out of the process, but drivers valued what the despatcher provided. They could ask for directions not well-covered by map apps e.g. specific buildings; and especially they sought help when there was a problem; particularly to summon help from fellow taxi drivers.

This latter was a recurrent interview theme: continuing presence and importance of driver groupings. Some of these were formal such as the unions which organised protests against Uber. Others were small, informal groups called via the radio - and rapidly responding - for example if a driver faced an aggressive or non-paying customer. These acted as a counter-balance to what would have been the 'natural' structural relations of the new regime; an atomised and automated relation just between individual drivers and the digital platform. Even EasyTaxi itself had countered this because it organised feedback channels between the company and the drivers: not just email and social media but periodical focus groups to get feedback on the app specifically and more generally on the function of the platform-based approach. Passengers similarly - who could only contact the old TOCs via the despatchers on the main phone number - were given multiple contact channels: in-app feedback, email, social media and a call centre.

Finally, if we turn to institutions, we can see a regulatory shift. The quotidian regulation of drivers used to come via owners or TOCs but it was fairly loose, informal and sometimes rather capricious. Under the new regime, registration procedures with EasyTaxi are much stricter than those with the TOCs. Operational regulation of drivers' actions is undertaken - often algorithmically - formally and objectively by the platform. Given EasyTaxi's dominant market position, drivers no longer have the option of cleaning their records by quitting and registering with a different platform as they could do with TOCs. So driver behaviour is more tightly constrained than previously.

In terms of discourse, there has been a shift towards more positive framing: not just EasyTaxi's press releases finding their way into the media but the positive reactions of drivers and passengers towards the app, with international travellers, for example, continuously recommending use of EasyTaxi as a way to stay safe in Bogotá. However, reflecting the legacy of the old regime either in the perception or reality of relations, negative sentiments were not far from the surface: ET's senior manager describing taxi drivers as "gang bangers and very quarrelsome"; passengers complaining 
about continuation of poor practices such as bad driving and overcharging; and drivers concerned that EasyTaxi could be as monopolistic as the TOCs.

This last point reflects a broader issue of what does not change. Uber requires a complete change: new vehicles, new licensing, new driver selection, etc and runs a dedicated and stand-alone service. But EasyTaxi works with and does not require change to, many of the features of the pre-existing regime. Regulatory oversight remains the same: EasyTaxi itself may be ICT Ministry-regulated, but taxis and drivers using the app remain under the jurisdiction of the same and various transport-related government agencies. Owners and drivers - allowing for exclusion of some "rotten apples" who cannot work with the new system - remain the same. And, by allowing drivers to use EasyTaxi as one of multiple booking systems, even TOCs were not head-on excluded: indeed, affiliation to a TOC remains an operational requirement for drivers and is the only explanation for their continuing existence. Just that, like the boiled frog, the TOCs are being slowly weakened and in time are likely to be superseded.

\section{Conclusions}

Growth of digital platforms in developing countries has not yet been matched by growth in research on this phenomenon; particularly conceptualised analysis of implementation and impact. A first contribution of this paper is the demonstrated relevance of understanding successful platforms as socio-technical transitions, and analysing them using the multi-level perspective.

Turning to our initial research question, the rapidity of transition from a call- to platform-based booking system for taxis in Bogotá emerges from the MLP as deriving from two main factors: the push of pressures within the landscape and the pre-existing regime that was matched by the pull of utility of the application for two key groups: drivers dissatisfied with their treatment by TOCs; passengers dissatisfied with service and security standards. But it also required enablers: landscape enablers of a necessary technological infrastructure; design enablers of incremental rather than discontinuous change; and implementation enablers in effective handling of potential barriers of technology, skills, knowledge, regulation and competition.

At the time of research, the transportation regime in Bogotá still had a hybrid format; mixing the old radio-based, TOC-dominated regime and the new app-based, platform-dominated regime. In part, this was a hybridity of transition; moving from the old to the new. But it was also a hybridity of design: EasyTaxi, unlike Uber, working within existing regulations and processes such as metered fares. And it was a hybridity of choice shaped particularly by the context of insecurity and mistrust that has pervaded transport in Bogotá: drivers continuing rental and use of radios; continuing strength of informal driver groups; even design decisions like the provision of an EasyTaxi call centre for passengers.

Notwithstanding its hybrid nature, we can already identify three impacts associated with introduction of this platform that help address our second question. First, datafication, with the capture, storage and analysis of digital data about many aspects of personal transportation that was previously lost in the ether or at least the value of 
which was not being captured. Two other impacts flow from this datafication. There has been a formalisation of some processes; particularly the before, during and after of passenger journeys, and some aspects of the management of drivers. This was in part a reaction against institutional informalities that are typical of developing countries.

As a final impact, one can see some shifts in power as a result of the platform's introduction. Passengers have been empowered to some extent thanks to the new data flows which help address the previous informational uncertainty and nescience which had fed fear and insecurity about travel in Bogotá. But the key change has been some transfer of power from the old taxi operating companies to the platform. Not merely due the declining market share of the former but also the loss of value of the resources they control. And also due to the significant value of the data the platform now owns, the transfer of responsibility for driver management to the platform's algorithms, and the more positive discourse that circulates about EasyTaxi.

One may also comment on what has not changed. Although they have been happy with the platform to date, the position of drivers has not changed much in terms of power. Through their support groups and use of the radio, they have acted to resist some potential loss of power to the platform. However, the emergence of EasyTaxi as a virtual monopoly in the app-booking market is a threat, with potential for "Meet the new boss. Same as the old boss" in terms of the power to exploit drivers that has been seen in other markets. Fortunately, Uber is around to - switching expressions - act as bad cop to EasyTaxi's good cop.

\section{References}

1. Avelino, F., Grin, J., Pel, B., \& Jhagroe, S. (2016). The politics of sustainability transitions. Journal of Environmental Policy \& Planning, 18(5), 557-567.

2. AWS (2015) About EasyTaxi, Amazon Web Services, Seattle, WA

3. Ballen Pachon, L. F. (2012) La Fiebre Amarilla en Bogotá: Los Taxímetros Fuera de Control, Universidad del Rosario, Bogotá

4. Benbasat, I., Goldstein, D. K., \& Mead, M. (1987). The case research strategy in studies of information systems. MIS Quarterly, 11(3), 369-386.

5. Constantinides, P., Henfridsson, O., \& Parker, G. G. (2018). Introductionplatforms and infrastructures in the digital age, Information Systems Research, 29(2), 381-400

6. de Reuver, M., Sørensen, C., \& Basole, R. C. (2018). The digital platform: a research agenda. Journal of Information Technology, 33(2), 124-135.

7. Fink, H. A. B. F. (2011) Corrupción en la policía de tránsito. Una primera aproximación a través de entrevistas con taxistas colombianos. Relaciones, 32(126), 67-85.

8. Geels, F.W. (2002). Technological transitions as evolutionary reconfiguration processes: a multi-level perspective and a case-study. Research Policy, 31(8), 1257-1274.

9. Geels, F.W. (2004). From sectoral systems of innovation to socio-technical systems: Insights about dynamics and change from sociology and institutional theory. Research Policy, 33(6-7), 897-920. 
10. Geels, F. W. (2010). Ontologies, socio-technical transitions (to sustainability), and the multi-level perspective. Research Policy, 39(4), 495-510.

11. Geels, F. W. (2011). The multi-level perspective on sustainability transitions: Responses to seven criticisms. Environmental Innovation and Societal Transitions, 1(1), 24-40.

12. Geels, F. W. (2014). Regime resistance against low-carbon transitions: introducing politics and power into the multi-level perspective. Theory, Culture \& Society, 31(5), 21-40.

13. Gonzalez, M.C. (2018) Easy Taxi y Tappsi se fusionan y duplicarían su capacidad, Portafolio, 11 Jun

14. Griffin, O. (2016) Uber’s Colombian speed bumps, TechCrunch, 24 Mar

15. Heeks, R. (2010) An ICT4D journal ranking table, Information Technologies \& International Development, 6(4), 71-75

16. Ibanez Perez, M. P. (2012). Viabilidad Técnica y Financiera del Servicio de Taxis en el Sistema Integrado de Transporte Público, Universidad Nacional de Colombia, Bogotá

17. ITU (2018) ICT Eye, International Telecommunication Union, Geneva

18. Koskinen, K., Bonina, C. \& Eaton, B. (2018) Digital Platforms in the Global South, DIODE Paper no.8, CDI, University of Manchester, UK

19. McConnell, K, (2011) Brazilian entrepreneurs innovate with smartphones, US Mission Geneva, 23 Nov

20. Meltzer, J.P. \& Marulanda, C.P. (2016) Digital Colombia, Brookings Institution, Washington, DC

21. Moitra, A., Kumar, A., \& Seth, A. (2018). An analysis of community mobilization strategies of a voice-based community media platform in rural India. Information Technologies \& International Development, 14, 116-133.

22. Muse, T. (2013) The danger of the millionaire ride, Newsweek, 26 Jun

23. Oliveira, R. (2013) Dicas de Tallis Gomes (Ceo do EasyTaxi) sobre como criar uma startup de sucesso, SmallData, 8 Nov

24. Rodriguez-Valencia, A. (2014) Taxicab operation in Bogotá, Colombia, Transportation Research Record, 2416(1), 92-99

25. Saldana, J., 2009. The Coding Manual for Qualitative Researchers, Sage, London

26. Scheller, F. (2012) 'App' de táxi recebe aporte de R\$ 10 milhões, Estadao, 13 Oct

27. Scott, W.R. (2014) Institutions and Organizations, 4th edn., Sage, Los Angeles, CA

28. Stewart, E. (2013) Easy Taxi recibió inversión de US\$15 millones de Rocket Internet, PulsoSocial, 25 Jun

29. Surie, A., \& Koduganti, J. (2016). The emerging nature of work in platform economy companies in Bengaluru, India: The case of Uber and Ola Cab drivers. E-Journal of International and Comparative Labour Studies, 5(3)

30. Wade, J. (2017) National taxi driver protest against Uber clogs roads across Colombia, Finance Colombia, 10 May

31. Williams, M. D., Dwivedi, Y. K., Lal, B., \& Schwarz, A. (2009). Contemporary trends and issues in IT adoption and diffusion research. Journal of Information Technology, 24(1), 1-10. 